\title{
CROSS-BORDER TRANSFERS OF PERSONAL DATA AFTER SCHREMS II: SUPPLEMENTARY MEASURES AND NEW STANDARD CONTRACTUAL CLAUSES (SCCs)
}

\author{
MARCELO CORRALES COMPAGNUCCI, ${ }^{*}$ MATEO ABOY, ${ }^{\dagger}$ TIMO MINSSEN ${ }^{\ddagger}$
}

This article analyses the legal challenges of international data transfers resulting from the recent Court of Justice of the European Union (CJEU) decision in Case C-311/18 Data Protection Commissioner v Facebook Ireland Limited, Maximillian Schrems (Schrems II). This judgement invalidated the EU-US Privacy Shield Framework but upheld the use of standard contractual clauses (SCCs). However, one caveat is that organisations would have to perform a case-by-case assessment on the application of the SCCs and implement 'supplementary measures' to compensate for the lack of data protection in the third country, where necessary. Regrettably, the CJEU missed the opportunity to specify what exactly these 'supplementary measures' could be. To fill this gap, the European Data Protection Board (EDPB) adopted guidelines on the measures that supplement transfer tools to ensure compliance with the EU level of protection of personal data. In addition, on June $4^{\text {th }}, 2021$ the European Commission issued new SCCs which replaced the previous SCCs that were adopted under the previous Data Protection Directive 95/46. These new developments have raised the bar for data protection in international data transfers. In this article, we analyse the current regulatory framework for cross-border transfers of EU personal data and examine the practical considerations of the emerging post-Schrems II legal landscape.

\section{INTRODUCTION}

One explicit goal of the General Data Protection Regulation (GDPR) ${ }^{1}$ is to guarantee the free flow of personal data between EU Member States. Additionally, the GDPR contemplates the possibility of transferring personal data to a third country - a country outside of the European

\footnotetext{
* Associate Professor at the Centre for Advanced Studies of Biomedical Innovation Law (CeBIL), Faculty of Law (UCPH). Acknowledgments: The research of all three co-authors for this contribution was supported by a Novo Nordisk Foundation grant for a scientifically independent Collaborative Research Programme in Biomedical Innovation Law (Grant agreement number NNF17SA0027784). Timo Minssen's Research has also been supported by the Wallenberg Foundations' 'Initiative for Humanistic and Social Scientific Research in AI and Autonomous Systems' (WASP-HS), see: https://portal.research.lu.se/portal/sv/projects/the-quantum-lawproject(4d675bed-6738-4f81-9b28-48746ada562b).html.

† Principal Research Scholar in Biomedical Innovation, Precision Medicine, AI \& Law at the Centre for Law, Medicine and Life Sciences (LML), Faculty of Law, University of Cambridge \& Affiliated Professor \& Fellow at CeBIL, Faculty of Law, University of Copenhagen (UCPH).

¥ Law Professor and the Founding Director for the Centre for Advanced Studies of Biomedical Innovation Law (CeBIL), Faculty of Law (UCPH). He is also affiliated as a guest researcher with Lund University.

${ }^{1}$ Regulation (EU) 2016/679 of the European Parliament and of the Council of 27 April 2016 on the protection of natural persons with regard to the processing of personal data and on the free movement of such data and repealing Directive 95/46/EC (General Data Protection Regulation, GDPR) [2016] OJ L 119/1.
} 
Economic Area (EEA) - or an international organisation, provided that importers and exporters can guarantee that data will be protected under the same European standards. GDPR provisions for international data transfers also include onward transfers. For instance, from a processor to a sub-processor in a third country outside the EEA. ${ }^{2}$

The current legal landscape to transfer personal data outside of the EEA as set out in the GDPR includes the following mechanisms:

i. Adequacy decisions (Art. 45 GDPR). Adequacy decisions are based on assessments that third country laws and practices guarantee the same level of European standard protection. The effect of such decisions is that personal data can flow without restrictions and any further additional safeguards. In other words, transfers to the countries in this list will be assimilated to intra-EU transmissions of data. ${ }^{3}$

ii. Appropriate safeguards (Art. 46 GDPR). In the absence of adequacy decisions, organisations involved in the cross-border transfers must implement 'appropriate safeguards' (ie, Standard Contractual Clauses (SCCs), Binding Corporate Rules (BCRs), codes of conducts, certification mechanisms and ad hoc contractual clauses) to ensure that the level of protection is not undermined. ${ }^{4}$

iii. Derogations (Art. 49 GDPR). In the absence of an adequacy decision or appropriate safeguards, there are specific situations (eg, the transfer is necessary for important reasons of public interest) where derogations may be used but these have an exceptional nature and are subject to strict conditions such as occasional and non-repetitive processing activities. ${ }^{5}$

Recent developments, including the Schrems II decision, the follow-on European Data Protection Board (EDPB) Recommendations on measures that supplement transfer tools to ensure compliance with the EU level of protection of personal data, ${ }^{6}$ and the new SCCs for the transfer of personal data to third countries ${ }^{7}$ issued by the European Commission (EC) on June $4^{\text {th }}, 2021$, have raised a wave of debates and concerns among data protection professionals.

\footnotetext{
${ }^{2}$ Eduardo Unstaran, 'International Data Transfers' in Eduardo Ustaran (ed), European Data Protection: Law and Practice (2nd edn, IAPP Publication, 2019), 527.

${ }^{3}$ See GDPR (n 1 ) art 45. See also Commission, 'Adequacy Decisions: How the EU determines if a non-EU country has an adequate level of data protection' < https://ec.europa.eu/info/law/law-topic/dataprotection/international-dimension-data-protection/adequacy-decisions_en> accessed 9 October 2021.

${ }^{4}$ See GDPR (n 1) art 46. The transfer tools may require additional 'supplementary measures' to ensure essentially equivalent level of protection. See Case C-311/18 Facebook Ireland and Schrems (Schrems II) ECLI:EU:C:2020:559, paras 130 and 133.

${ }^{5}$ See GDPR (n 1) art 49.

${ }^{6}$ European Data Protection Board (EDPB), 'Recommendations on measures that supplement transfer tools to ensure compliance with the EU level of protection of personal data' ('EDPB Recommendations 01/2020') adopted on 10 November 2020, <https:/ /edpb.europa.eu/our-work-tools/ourdocuments/recommendations/recommendations-012020-measures-supplement-transfer_en $>$ accessed 9 October 2021.

${ }^{7}$ European Commission implementing decision of 4 June 2021 on standard contractual clauses for the transfer of personal data to third countries pursuant to Regulation (EU) 2016/679 of the European Parliament and of the Council, C(2021) 3972 final.
} 
While the Schrems II ruling ultimately found that the SCCs were valid, the Court also noted that the receiving country's laws could potentially undermine the protections in the SCCs, exacerbating the uncertainties and risks for organisations relying on this transfer tool. ${ }^{8}$ The new SCCs provide more flexibility and ameliorates some of the shortcomings of the previous SCCs. They raise the standard of data protection and include stricter rules for data importers and exporters, in particular extensive obligations for data importers acting as controllers. ${ }^{9}$

In light of these new challenges, this article aims to analyse the emerging legal framework for international transfers of personal data. The paper is structured as follows. Section 2 elucidates the background and main issues raised in the Schrems cases. Section 3 then provides a synopsis of the current legal framework and data protection guidance for cross-border transfers after the Schrems II judgment. This provides the basis for Section 4, which delivers a discussion of the practical implications of these developments including a discussion of how to best navigate the new legal environment for international data transfer. This will allow us to draw conclusions in Section 5.

\section{THE INVALIDATION OF THE SAFE HARBOUR AGREEMENT AND THE EU-US PRIVACY SHIELD IN SCHREMS I \& II}

In 2013, Austrian citizen and privacy activist Maximilian Schrems filed a legal suit with the Irish Data Protection Commission (DPC) against Facebook (Schrems I) ${ }^{10}$ and requested to prohibit or suspend the transfer of his personal data from Facebook Ireland to the United States. He considered that the law and practice of the United States did not warrant adequate protection of the personal data held in its territory against the surveillance activities that were engaged in there by the public authorities such as the US National Security Agency (NSA). ${ }^{11}$

The DPC, however, rejected the complaint on the grounds of, in particular, Decision 2000/520 (Safe Harbour Agreement) which ensured an adequate level of protection of personal data transferred between the EU and the US. Mr. Schrems contested the decision of the DPC and the Irish High Court referred the case to the CJEU for a preliminary ruling on the interpretation and validity of the Safe Harbour Framework. ${ }^{12}$

In addition to the lack of informed consent and the failure to provide legal remedies for individuals, Mr. Schrems argued that US surveillance laws (such as section 702 of the Foreign

\footnotetext{
${ }^{8}$ Aloke Chakravarty and Mary Colleen Fowler, 'What Schrems are Made Of: The European Commission Adopts New Standard Contractual Clauses for International Data Transfers Covered by GDPR' (JDSUPR A, 30 June 2021) < https://www.jdsupra.com/legalnews/what-schrems-are-made-of-the-european-3977830/ $\geq$ accessed 9 October 2021.

${ }^{9}$ Carol Umhoefer and Andrew Serwin, 'European Commission's standard contractual clauses: extensive new requirements coming for US businesses receiving EU personal data subject to GDPR' (DLA Piper, 8 June 2021)

<https://www.dlapiper.com/en/us/insights/publications/2021/06/european-commissions-standardcontractual-clauses-extensive-new-requirements $/ \geq$ accessed 9 October 2021.

${ }^{10}$ Case C-362/14 Maximillian Schrems vs Data Protection Commissioner (Schrems I) ECLI:EU:C:2015:650.

11 'EU-US Data Transfers' (NOYB) < https:// noyb.eu/en/project/eu-us-transfers $\geq$ accessed 9 October 2021.

12 Timo Minssen and others, 'The EU-US Privacy Shield Regime for Cross-Border Transfers of Personal Data under the GDPR: What are the Legal Challenges and How Might These Affect Cloud-based Technologies, Big Data, and AI in the Medical Sector?' (2020) 4(1) European Pharmaceutical Law Review 34, 3941.
} 
Intelligence Surveillance Act and Executive Order 12333) and US programs disclosed by the Snowden revelations ${ }^{13}$ such as PRISM, ${ }^{14}$ allowed US authorities to access personal data from US Big Tech companies. The CJEU agreed with the plaintiff and decided to overturn the Safe Harbour Agreement in 2015, thereby making illegal to transfer personal data under this framework. The CJEU held that this was a violation to European privacy laws and the fundamental principles enshrined in Articles 7, 8 and 47 of the Charter of Fundamentals Rights of the European Union (CFR). ${ }^{15}$

After the invalidation of the Safe Harbour Agreement, Facebook and other companies then changed to the SCCs to claim legal basis for the transfer of personal data outside of the EU. ${ }^{16}$ The US and European authorities signed another agreement which would compensate the failings of Safe Harbour. This new agreement was the so-called EU-US Privacy Shield Framework, ${ }^{17}$ whereby US-based companies could join by committing to the framework requirements and by submitting a self-certification to the US Department of Commerce. The EU-US Privacy Shield Framework included a list of requirements such as the submission of a privacy policy with specific details. In general, the framework required greater transparency, oversight and redress mechanisms, including the creation of an ombudsman to investigate complaints as well as arbitration and alternative dispute resolution (ADR) mechanisms. ${ }^{18}$ In effect, the Privacy Shield enabled EU to US cross-border transfers under Art. 45 GDPR (as a limited adequacy decision). ${ }^{19}$

By an amended complaint in December 2015, Mr. Schrems challenged the validity of Facebook's use of SCCs and requested the DPC to prohibit or suspend the transfer of his personal data to Facebook Inc. Finally, in July 2020, the CJEU in Case C-311/18 Data Protection Commissioner v Facebook Ireland Limited, Maximillian Schrems (Schrems II) ${ }^{20}$ rendered the EU - US Privacy Shield invalid and upheld the validity of the SCCs.

Nevertheless, the Court required a 'case-by-case' analysis on the application of the SCCs. Controllers and processors exporting data need to verify if the law and practice of the third country impinges on the effectiveness of the appropriate safeguards established in Art. 46 GDPR. It follows from the Schrems II judgement that data exporters need to implement

\footnotetext{
${ }^{13}$ Barton Gellman, Dark Mirror: Edward Snowden and the American Surveillance State (Penguin Press 2020).

${ }^{14}$ Nicholas Watt, 'Prism Scandal: European Commission to Seek Privacy Guarantees from the US' (The Guardian, 10 June 2013) < https://www.theguardian.com/world/2013/jun/10/prism-european-commissions-privacyguarantees $\geq$ accessed 9 October 2021 .

${ }^{15}$ Marcelo Corrales Compagnucci and others, 'Lost on the High Seas Without a Safe Harbor or a Shield? Navigating Cross-Border Transfers in the Pharmaceutical Sector After Schrems II Invalidation of the EU-US Privacy Shield' (2020) 4(3) European Pharmaceutical Law Review 153, 154-155.

${ }^{16}$ Leslie Hamilton, 'The Legal Environment' in Leslie Hamilton and Philip Webster (eds), The International Business Environment (4th edn, OUP 2018), 341.

${ }^{17}$ Commission Implementing Decision (EU) 2016/1250 of 12 July 2016 pursuant to Directive 95/46/EC of the European Parliament and of the Council on the adequacy of the protection provided by the EU-US Privacy Shield (notified under document C(2016) 4176).

18 Timo Minssen and others (n 12) 38.

${ }^{19}$ Laura Bradford, Mateo Aboy and Kathleen Liddell, 'International Transfers of Health Data between the EU and USA: A Sector-Specific Approach for the USA to Ensure an 'Adequate' Level of Protection' (2020) 7(1) Journal of Law and the Biosciences 1.

${ }^{20}$ Schrems II (n 4).
} 
'supplementary measures' that fill the gaps and bring it up to the level required by EU law. Unfortunately, the CJEU did not define or specify what these 'supplementary measures' are. ${ }^{21}$ This permeated in heated debates and a wave of guidelines and recommendations on those additional safeguards.

\section{RECENT DEVELOPMENTS AFTER SCHREMS II}

After the Schrems II decision, on November $10^{\text {th }}, 2020$, the EDPB issued a six-step-approach Recommendations on measures that supplement transfer tools to ensure compliance with the EU level of protection of personal data. The EDPB Recommendations are intended to help organisations comply with the requirements established by the CJEU in Schrems II. Following the Recommendations, on June $4^{\text {th }}, 2021$, the European Commission issued the long-awaited new SCCs for the transfer of personal data to third countries. ${ }^{22}$ These two new developments are further explained below:

\subsection{EDPB RECOMMENDATIONS: A SIX-STEP APPROACH}

The EDPB recommends organisations to follow six steps to transfer personal data to third countries outside of the EEA:

Step 1 - Know your data transfers: Data exporters should be fully aware of their transfers of personal data to third countries, including onward transfers. Mapping and recording all data transfers can be a complex task, however, this is necessary to ensure an essentially equivalent level of protection wherever it is processed. Data exporters should record all processing activities, keep data subjects informed and make sure it is in line with the principle of data minimisation. ${ }^{23}$

Step 2 - Identify the transfers tools you are relying on: A second step is to identify the transfer tools set out in Chapter V of the GDPR including: a) adequacy decisions; ${ }^{24}$ b) transfers tools containing 'appropriate safeguards' of a contractual nature in the absence of adequacy decisions (such as SCCs, Binding Corporate Rules (BCRs), codes of conducts, certification mechanisms and ad hoc contractual clauses) $;{ }^{25}$ and, c) derogations. ${ }^{26}$ If your

${ }^{21}$ Laura Bradford, Mateo Aboy and Kathleen Liddell, 'Standard Contractual Clauses for Cross-Border Transfers of Health Data After Schrems II' (2020) 8(1) Journal of Law and the Biosciences 1.

${ }^{22}$ European Commission implementing decision of 4 June 2021 on standard contractual clauses for the transfer of personal data to third countries pursuant to Regulation (EU) 2016/679 of the European Parliament and of the Council, C(2021) 3972 final.

${ }^{23}$ EDPB Recommendations $01 / 2020$ (n 6), 8-9.

${ }^{24}$ See GDPR (n 1 ) art 45. Adequacy decisions may cover a country as a whole or be limited to a part of it. If you transfer data to any of these countries, there is no need to take any further steps described in this section. The EU Commission has so far recognised only twelve countries which can offer adequate level of protection. These countries are: Andorra, Argentina, Canada (commercial organisations), Faroe Islands, Guernsey, Israel, Isle of Man, Japan, Jersey, New Zealand, Switzerland and Uruguay. As of March 2021, adequacy talks were concluded with South Korea. See Commission, Adequacy decisions (n 3).

${ }^{25}$ GDPR (n 1) art 46. The transfer tools may require additional 'supplementary measures' to ensure essentially equivalent level of protection. See Schrems II (n 4), paras 130 and 133.

${ }^{26}$ GDPR (n 1) art 49. 
data transfer does not fall under either a) 'adequacy decisions' or c) 'derogations', you need to continue to step $3 .^{27}$

Step 3 - Assess whether Art. 46 of the GDPR transfer tool you are relying on is effective in light of all circumstances of the transfer: Utilising a transfer tool under Art. 46 of the GDPR may not be sufficient if your transfer tool is not 'effective' in practice. 'Effective' means that the level of protection is essentially equivalent to that afforded in the EEA. ${ }^{28}$ Data exporters should carry out a Transfer Impact Assessment (TIA) to assess - in collaboration with the importer - if the law and practice of the third country where the data is being transferred may impinge on the effectiveness of the appropriate safeguards of the Art. 46 in the context of the specific transfer. In performing this assessment, different aspects of the third country legal system should be taken into account, in particular whether public authorities can access personal data and, in general, those elements enlisted in Art. $45(2)$ of the $\mathrm{GDPR}^{29}$ such as the rule of law situation and respect for human rights in that third country. ${ }^{30}$

Step 4 -Adopt supplementary measures: If the TIA revealed that your Art. 46 tool is not 'effective', data exporters - in collaboration with the importers, where appropriate need to consider if 'supplementary measures' exist. By definition, supplementary measures are 'supplementary' to the safeguards that the transfer tools already provide. In other words, if added to the safeguards contained in Art. 46, could ensure that the data transferred is afforded an adequate level of protection in the third country which is essentially equivalent to the European standard. Exporters need to identify on a case-bycase basis which supplementary measures could be effective taking into account the previous analysis in steps 1,2 and $3 .^{31}$

Step 5 - Formal procedural steps: Make sure to take any formal procedural steps in case you have identified effective supplementary measures, which may vary depending on the transfer tool used or expected to be used. For instance, if data exporters intend to put in place supplementary measures in addition to the SCCs, there is no need to request an approval from the supervisory authority as long as the supplementary measures do not contradict, directly or indirectly, the SCCs and are enough to ensure that the level of protection guaranteed by the GDPR is not compromised in any way. ${ }^{32}$

Step 6 - Re-evaluate at appropriate intervals: The last step put forward by the EDPB is to monitor and review, on an ongoing basis, if there are new developments in the third country where data was transferred which could affect the initial assessment of the level of protection of the third country and the supplementary measures taken based on the TIA and the specific transfer. This is also in line with the principle of accountability which is a continuous obligation as set out in Art. 5(2) GDPR. Data exporters, in

${ }^{27}$ EDPB Recommendations 01/2020 (n 6) 9-11.

${ }^{28}$ See Schrems II (n 4), para 105 and second finding.

29 ibid para 104.

${ }^{30}$ EDPB Recommendations 01/2020 (n 6) 12.

31 ibid 15-17.

32 ibid 17-18. 
collaboration with the importers, should put in place sufficiently sound mechanisms to ensure that any transfer relying on the SCCs are suspended or prohibited if the supplementary measures are no longer effective in that third country or where those clauses are breached or impossible to honour. ${ }^{33}$

\subsection{NEW STANDARD CONTRACTUAL CLAUSES (SCCs)}

SCCs have a dual nature as a private contract and public instrument granting enforceable GDPR rights to third parties and subject to the oversight of the EU data protection authorities. They are intended to provide 'appropriate safeguards' under Art. 46 GDPR by creating legal obligations on the exporters and importers to ensure an appropriate level of data protection and GDPR compliance with respect to personal data transferred to countries which do not have adequacy decision (Art. 45 GDPR)..$^{34}$ On June $4^{\text {th }}, 2021$, the European Commission released updated versions of the SCCs which reflect the GDPR requirements and take into account the legal analysis in the Schrems II decision. The Commission adopted two sets of SCCs, one for use between controllers and processors in the EU/EEA ${ }^{35}$ and one for the transfer of personal data to third countries. ${ }^{36}$

The main innovations and salient points of the new SCCs can be summarised as follows:

A modular approach: Contrary to the prior set of SCCs which offered restricted possibilities of data transfers and separate sets of clauses, the new SCCs provide more flexibility for complex processing chains through a 'modular approach'. This means that data exporters and data importers can now choose the module that best applies to their needs within the same agreement. ${ }^{37}$ In addition to the previously existing options for data transfers scenarios from 'controller to controller' and 'controller to processor', there are now two more modules governing data transfers from 'processor to processor' ${ }^{38}$ and 'processor to controller'. ${ }^{39}$

Geographic scope of application: The new SCCs have a broader scope of application in comparison to the older version which only allowed the data exporter be a party if it was established in the EEA. This created barriers for data export compliance where a data exporter was established outside of the EEA but still subject to the GDPR by virtue of the GDPR's extraterritorial scope in Art. 3(2). According to the new SCCs, the data

\footnotetext{
${ }^{33}$ EDPB Recommendations 01/2020 (n 6) 18-19.

${ }^{34}$ Ian Lloyd, Information Technology Law (7th edn, OUP 2014), 183.

${ }^{35}$ European Commission, Standard Contractual Clauses for controllers and processors in the EU (4 June 2021), available at: https://ec.europa.eu/info/law/law-topic/data-protection/publications/standard-contractual-clausescontrollers-and-processors accessed 9 October 2021.

36 ibid.

${ }^{37}$ Module 1: controllers to controllers, Module 2: controllers to processors, Module 3: processors to processors and Module 4: processors to controllers.

38 This is, for example, when there is a processor such as a cloud service provider located in the EEA and transfers data to another processor such as an infrastructure provider in the US.

${ }^{39}$ In this case, the data is transferred back to the controller (back to 'its origin'). This is also sometimes referred as 'reverse transfer'.
} 
exporter can also be a non-EEA entity. This provision, along with the modular approach, allows to cater any kind of data transfer between parties, despite of their data processing role or place of establishment. ${ }^{40}$

Multiparty clauses and docking clause: The new SCCs allow for multiple data exporting parties to contract (eg, within corporate groups or party collaborations) and for new parties to be added to them over time through the so-called 'docking clause' (Clause 7). ${ }^{41}$ This clause is optional and allows additional third parties which are not (yet) a part of the agreement to join and sign up with the agreement of the other parties without having to conclude separate contracts. Third parties may now join by completing the Appendix with details of the transfer, technical and organisational measures implemented and a list of sub-processors where relevant - and sign Annex 1.A. ${ }^{42}$ This new mechanism provides a more flexible approach for the existing data processing practices, in particular in the context of acquisitions, additional corporate entities, and sub-processors. ${ }^{43}$

Data Protection Impact Assessment (DPIA): In response to the Schrems II ruling, companies must perform and document a mandatory DPIA that should include a data transfer impact assessment (TIA) and make it available to the competent supervisory authority upon request. The TIA should assess, for instance: i) whether the laws of the third country into which the data is imported could conflict with the SCCs and the GDPR, ii) whether any additional safeguards are necessary to enhance data protections (eg, implement supplementary technical measures). For example, a TIA should determine whether the data importer is subject to the US Foreign Intelligence Surveillance Act Section 702 (FISA 702). ${ }^{44}$ The TIA should be monitored on a continuous basis and updated in light of any changes in the laws of the third country.

Security measures: Annex II of the new SSCs provides a more detailed list of examples of the technical and organisational measures necessary to ensure an appropriate level of protection, including measures to ensure the security of the data. While the list is nonexhaustive, it includes measures to provide assistance to the parties. According to Annex II, the technical and organisational measures must be described in 'specific (and not generic) terms'. This includes, in particular, any relevant 'certifications' to ensure an appropriate level of security, taking into consideration 'the nature, scope, context and

\footnotetext{
${ }^{40}$ Phillip Lee, 'The Updated Standard Contractual Clauses: A New Hope?’ (LAPP, 7 June 2021)

< https://iapp.org/news/a/the-updated-standard-contractual-clauses-a-new-hope/> accessed 9 October 2021.

41 ibid.

42 Alexander Milner-Smith, 'New Standard Contractual Clauses - what do you need to know?' (Lewis Silkin, 14 June 2021) < https:/ / www.lewissilkin.com/en/insights/new-standard-contractual-clauses-what-do-you-needto-know $>$ accessed 9 October 2021.

${ }^{43}$ Martin Braun and others., 'European Commission adopts and publishes new Standard Contractual Clauses for international transfers of personal data' (WilmerHale, 7 June 2021)

<https://www.wilmerhale.com/en/insights/blogs/wilmerhale-privacy-and-cybersecurity-law/20210607european-commission-adopts-and-publishes-new-standard-contractual-clauses-for-international-transfers-ofpersonal-data $\geq$ accessed 9 October 2021.

${ }^{44}$ Caitlin Fennessy, 'Data transfers: questions and answers abound, yet solutions elude' (LAPP, 12 February 2021)

<https://iapp.org/news/a/data-transfers-questions-and-answers-abound-yet-solutions-elude/> accessed 9

October 2021.
} 
purpose of the processing, and the risks for the rights and freedoms of natural persons.' The measures of pseudonymisation and encryption are at the top of the list. ${ }^{45}$

There are several other new practical features in the new SCCs toolbox which provide more flexibility and legal certainty to the parties involved, such as the possibility to choose the governing law and jurisdiction of any EU Member State. This is particularly useful when the SCCs cover multiple international data transfers and servers are located in different countries. The new SCCs contain significantly more requirements and obligations for data exporters and importers, particularly for importers acting as controllers. This is also more in line with the GDPR requirements. The new SCCs include, for instance, obligations to give notice to data subjects and to notify personal data breaches to EU authorities. ${ }^{46}$

\section{PRACTICAL CONSIDERATIONS}

The CJEU ruled in Schrems II that the SCCs remain as a valid cross-border transfer mechanism provided the parties involved in the transfer implement the necessary 'supplementary measures' whenever they are needed to ensure substantially equivalent data protection by providing 'appropriate safeguards' to rectify any data protection gaps that undermine equivalency in the third countries. ${ }^{47}$ Regrettably, the Court failed to provide any meaningful guidance about what specific supplementary measures might be required in this regard. In an attempt to fill this gap, the EDPB Recommendations provide a non-exhaustive list of factors to identify - in collaboration with the importer - which supplementary measures would be most effective in protecting the data transferred. The new SCCs provide a useful instrument to support crossborder data transfers in many situations (eg, cross-border transfers of clinical trial data).

SCCs are currently the primary mechanism for cross-border transfers of personal data among commercial entities. Unlike the country-specific adequacy rulings under Art. 45 GDPR which are at the purview of the Commission, SCCs were not designed as a stand-alone mechanism for data transfer based on the adequacy of data protection law in the country receiving the data. SCCs, and other Article 46 'appropriate safeguards,' such as Binding Corporate Rules (BCRs), were intended to offer an alternative and additive, multi-layered standard for data protection that utilises 1 ) the data protection law of the third party and addresses any gaps with respect to GDPR by adding 2) a customisable combination of legal, technological (eg, security measures), and organisational commitments to establish a safe and secure environment for cross-border data transfer beyond the EEA for situations where the third country does not have adequacy decision under Art. 45 GDPR. ${ }^{48}$

\footnotetext{
45 See Annex II Standard Contractual Clauses (n 35).

${ }^{46}$ Carol Umhoefer and Andrew Serwin, 'European Commission's standard contractual clauses: extensive new requirements coming for US businesses receiving EU personal data subject to GDPR' (DLA Piper, 8 June 2021), <https://www.dlapiper.com/en/us/insights/publications/2021/06/european-commissions-standardcontractual-clauses-extensive-new-requirements $/>$ accessed 9 October 2021.

47 Schrems II (n 4) paras 103, 134.

${ }^{48}$ Laura Bradford and others 'Standard Contractual Clauses for Cross-Border Transfers of Health Data After (n 21).
} 
The new SCCs are aligned with the GDPR and provide examples of technical and organisational measures in Annex III. They fill a long-existing gap in data protection law (since the former SCCs were adopted pre-GDPR), provide additional flexibility with regards to the permitted cross-border data-flows and help improve legal certainty for some international data transfers to third countries. It is expected that these modernised SCCs will enable businesses to account for a greater variety of complex data transfers and at the same time offering a safe exchange of personal data, adding uniformity and legal predictability to business transactions. ${ }^{49}$ That said, in situations where an importer is subject to FISA 702 or similar public surveillance questions still remain. Specifically, what supplementary measures would be considered sufficient in such situations by the supervisory authorities or CJEU? Arguably, in conjunction with the SCCs the controller should at least 1) implement robust data minimisation to ensure the absolute minimum data needed for processing is transferred to the third country, 2) completely deidentify and encrypt the data transferred to the third country (both in transit and at rest encryption), 3) keep the encryption and pseudonymisation keys in the EU/EEA under the legal, organisational, and technical control of an EU party not subject to FISA (or other surveillance regime), 4) consider implementing multi-party encryption and processing (eg, multi-party homomorphic encryption), 5) implement a full information security management system (ISMS) such as the ISO 27001, and 6) document all these measures as part of Annex III of the SCC.

The use of the term 'supplementary measures' by the CJEU is unfortunate, as all these measures are technically part of the SCC security annex and were already needed to comply with the Art. 32 GDPR security of processing in light of part of the risk-based assessment (eg, Art. 35 GDPR, which provides for the DPIA). Furthermore, pursuant to Art. 46 the SCC is the 'appropriate safeguard' and these so-called 'supplementary measures' are technically not 'supplementary'. Instead, they are the same security measures that have always been documented and incorporated by reference as part of the SCCs.

In addition, organisations will have to pay particular attention to the new ISO 27701, which is the latest international standard for data privacy information management in the ISO 27000 series. It is a certifiable extension to the ISO 27001 that attempts to help organisations in meeting the GDPR requirements when implementing a comprehensive privacy information management system (PIMS). Organisations that have already implemented the ISO 27001 ISMS are advised to add privacy and data protection controls in ISO 27701 to ensure appropriate levels of data protection, especially when involved in cross-border transfers of personal data. ${ }^{50}$

There is a limited number of technical measures that could help organisations using SCCs to provide the European level of protection when the data is flowing around the world and possibly subject to public surveillance. These include 1) the use of robust end-to-end encryption with one or more independent EU/EEA-based trustees securely holding the keys, and 2) multi-

${ }^{49}$ European Commission, European Commission adopts new tools for safe exchange of personal data (4 June 2021) <https://ec.europa.eu/commission/presscorner/detail/en/ip_21_2847> accessed 9 October 2021.

${ }^{50}$ Luke Irwin, 'An Introduction to ISO 27701: The International Standard for Data Privacy,' (IT Governance European Blog, 20 April 2021) < https://www.itgovernance.eu/blog/en/iso-27701-the-new-international-standardfor-data-privacy $\geq$ accessed 9 October 2021 . 
party homomorphic encryption. ${ }^{51}$ Both of these security measures are technical controls and should be implemented within an overall ISMS $^{52}$ and PIMS $^{53}$ that is properly scoped and regulatory stress-tested (eg, subject to regular enhanced penetration testing). Additionally, it is important for the ISMS/PIMS to be independently audited (eg, subject to third-party ISO27001/27701 certification audits).

\section{CONCLUSION}

Arguably, the new SCCs raised the bar for data protection and security in international data transfers. Adopting and complying with this new legal framework may result in substantive legal, organisational and technical requirements for some parties. Businesses and organisations need to identify which transfer tools are already in place and be ready to migrate them to the new SCCs and working with data importers or exporters to ensure they are compliant. They should follow a risk-based approach and be ready to perform a DPIA and TIA taking into account the EDPB Recommendations and new SCCs requirements. Considering the increasing importance of data driven technologies and the global flow of data, as well as the ever-fiercer competition of emerging markets with less restrictive data protection regulations, it remains to be seen how these developments will affect the competitiveness of the European data innovation landscape and industry in a great variety of sectors.

51 Marcelo Corrales Compagnucci and others, 'Homomorphic Encryption: The 'Holy Grail' for Big Data Analytics \& Legal Compliance in the Pharmaceutical and Healthcare Sector?', (2019) 3(4) European Pharmaceutical Law Review 144.

52 Information Security Management System (ISO 27001).

53 Privacy Information Management System (ISO 27701). 


\section{LIST OF REFERENCES}

Bradford L, Aboy M and Liddell K, 'International Transfers of Health Data between the EU and USA: A Sector-Specific Approach for the USA to Ensure an 'Adequate' Level of Protection' (2020) 7(1) Journal of Law and the Biosciences 1.

DOI: https://doi.org/10.1093/jlb/lsaa055

- - ' 'Standard Contractual Clauses for Cross-Border Transfers of Health Data After Schrems II' (2021) 8(1) Journal of Law and the Biosciences 1.

DOI: https://doi.org/10.1093/jlb/lsab007

Braun $\mathrm{M}$ and others, European Commission adopts and publishes new Standard Contractual Clauses for international transfers of personal data (7 June 2021), available at: https://www.wilmerhale.com/en/insights/blogs/wilmerhale-privacy-and-cybersecuritylaw/20210607-european-commission-adopts-and-publishes-new-standard-contractualclauses-for-international-transfers-of-personal-data accessed 9 October 2021.

Chakravarty A and Colleen Fowler M, 'What Schrems are Made Of: The European Commission Adopts New Standard Contractual Clauses for International Data Transfers Covered by GDPR' (30 June 2021), available at: https://www.jdsupra.com/legalnews/what-schrems-are-made-of-the-european-3977830/ accessed 9 October 2021.

Corrales Compagnucci M, Minssen T, Seitz C, Aboy M, 'Lost on the High Seas Without a Safe Harbor or a Shield? Navigating Cross-Border Transfers in the Pharmaceutical Sector After Schrems II Invalidation of the EU-US Privacy Shield' (2020) 4(3) European Pharmaceutical Law Review 154.

DOI: https://doi.org/10.21552/eplr/2020/3/5

Corrales Compagnucci M, Meszaros J, Minssen T, Arasilango A, Ous T, Rajarajan M, 'Homomorphic Encryption: The 'Holy Grail' for Big Data Analytics \& Legal Compliance in the Pharmaceutical and Healthcare Sector?' (2019) 3(4) European Pharmacentical Law Review 144.

DOI: https://doi.org/10.21552/eplr/2019/4/5

Fennessy C, Data transfers: questions and answers abound, yet solutions elude (12 February 2021), available at: https://iapp.org/news/a/data-transfers-questions-andanswers-abound-yet-solutions-elude/ accessed 9 October 2021.

Gellman B, 'Dark Mirror: Edward Snowden and the American Surveillance State' (Penguin Press 2020). 
Hamilton L, 'The Legal Environment' in Hamilton L and Webster P (eds) The International Business Environment, (4th edn, OUP 2018).

Irwin L, 'An Introduction to ISO 27701: The International Standard for Data Privacy,' (20 April 2021), available at: https:/ /www.itgovernance.eu/blog/en/iso-27701-the-newinternational-standard-for-data-privacy accessed 9 October 2021.

Lee P, 'The Updated Standard Contractual Clauses: A New Hope?’ (7 June 2021), available at: https://iapp.org/news/a/the-updated-standard-contractual-clauses-a-new-hope/ accessed 9 October 2021.

Lloyd I, Information Technology Law (7th edn, OUP 2014).

DOI: https://doi.org/10.1093/he/9780198702320.001.0001

Milner-Smith A, New Standard Contractual Clauses - what do you need to know? (14 June 2021), available at: https://www.lewissilkin.com/en/insights/new-standard-contractualclauses-what-do-you-need-to-know accessed 9 October 2021.

Minssen T, Seitz C, Aboy M, Corrales Compagnucci M, 'The EU-US Privacy Shield Regime for Cross-Border Transfers of Personal Data under the GDPR: What are the Legal Challenges and How Might These Affect Cloud-based Technologies, Big Data, and AI in the Medical Sector?' (2020) 4(1) European Pharmaceutical Law Review 39.

DOI: https://doi.org/10.21552/eplr/2020/1/6

Noyb, 'EU-US Data Transfers', available at: https://noyb.eu/en/project/eu-us-transfers accessed 9 October 2021.

Umhoefer C and Serwin A, 'European Commission's standard contractual clauses: extensive new requirements coming for US businesses receiving EU personal data subject to GDPR' (8 June 2021), available at:

https://www.dlapiper.com/en/us/insights/publications/2021/06/europeancommissions-standard-contractual-clauses-extensive-new-requirements/ accessed 9

October 2021.

Unstaran E, 'International Data Transfers' in European Data Protection: Law and Practice, 2nd Edition (IAPP Publication), 527.

Watt N, 'Prism Scandal: European Commission to Seek Privacy Guarantees from the US' (10 June 2013), available at: https://www.theguardian.com/world/2013/jun/10/prismeuropean-commissions-privacy-guarantees accessed 9 October 2021. 